\title{
DOWN-REGULATION OF SURFACE MONOCYTE LIPOPOLYSACCHARIDE-RECEPTOR CD14 IN PATIENTS ON CARDIOPULMONARY BYPASS UNDERGOING AORTA-CORONARY BYPASS OPERATION
}

\author{
G. Fingerle-Rowson, $\mathrm{MD}^{\mathrm{a}}$ \\ J. Auers ${ }^{\mathrm{a}}$ \\ E. Kreuzer, $\mathrm{MD}^{\mathrm{b}}$ \\ M. Labeta, $\mathrm{PhD}^{\mathrm{d}}$ \\ B. Schmidt ${ }^{\mathrm{a}}$ \\ W. Samtleben, MD \\ H. W. L. Ziegler-Heitbrock, $\mathrm{MD}^{\mathrm{c}}$ \\ M. Blumenstein, MD
}

\begin{abstract}
Objectives: Major operative trauma like aorta-coronary bypass operation may lead to postoperative immunodisturbance, putting the patient at an increased risk for infection and sepsis. The monocyte/macrophage system and the endotoxin receptor CD14 are important in the early recognition and elimination of invading bacteria. The aim of this study was to analyze changes in membrane-associated CD14 and soluble CD14 during and after cardiac involving cardiopulmonary bypass. Methods: We studied numbers of leukocytes, monocytes, and monocyte subpopulations, expression of monocyte membrane-associated CD14 and plasma levels of soluble CD14 in 10 patients ( $63 \pm 8$ years of age), who underwent elective cardiopulmonary bypass. Results: Cardiopulmonary bypass induced marked postoperative monocytosis, which was maximal 20 hours after the operation $(485 \pm 242$ cells/ $\mu$ l before, $1080 \pm 264$ cells/ $\mu \mathrm{l} 20$ hours after surgery). Expression of membrane-associated CD14 on classical CD14++ monocytes decreased significantly by $40 \%$, reaching a nadir 20 hours after surgery $(p<0.05)$. At the time of maximal membrane-associated CD14 suppression, the levels of soluble CD14 measured by enzyme-linked immunosorbent assay were clearly increased $(3.2 \pm 1.0 \mu \mathrm{g} / \mathrm{ml}$ before versus $5.6 \pm 1.0 \mu \mathrm{g} / \mathrm{ml} 20$ hours after, $p<0.001)$. No significant change of the percentage of small $(\alpha)$ and large $(\boldsymbol{\beta})$ forms of soluble CD14 was found. Conclusions: Cardiopulmonary bypass leads to reduced membrane-associated CD14 expression on peripheral blood monocytes and increased levels of soluble CD14 through shedding or secretion of membrane-associated CD14 from the cell surface. These findings indicate that bypass is associated with significant monocyte activation. (J Thorac Cardiovasc Surg 1998;115:1172-8)
\end{abstract}

Datic atients undergoing cardiopulmonary bypass (CPB) frequently manifest a generalized systemic inflammatory response syndrome. Clinically, these reactions are reflected in postoperative leukocytosis, fever, and extravascular fluid accumulation,

From the Departments of Internal Medicine $\mathrm{I}^{\mathrm{a}}$ and Cardiac Surgery, ${ }^{\mathrm{b}}$ Klinikum Grosshadern, and the Institute of Immunology, ${ }^{\mathrm{c}}$ University of Munich, Munich, Germany; and the Department of Medicine, University of Wales, ${ }^{\mathrm{d}}$ Cardiff, United Kingdom.

Supported by the Deutsche Forschungsgemeinschaft (SFB 217) and by the Veru Foundation.

Received for publication April 21, 1997; revisions requested June 6, 1997; revisions received Nov. 20, 1997; accepted for publication Nov. 20, 1997.

Address for reprints: Matthias Blumenstein, MD, Stiftsklinik Augustinum, Wolkerweg 16, 81375 München, Germany.

Copyright (C) 1998 by Mosby, Inc.

$0022-5223 / 98 \$ 5.00+0 \quad \mathbf{1 2 / 1 / 8 7 8 0 0}$ which may be associated with prolonged recovery and occasionally with serious organ dysfunction. ${ }^{1-3}$ Current knowledge suggests that activation of circulating leukocytes, platelets, and vascular wall components, such as endothelial cells, during CPB is involved in this inflammatory response. However, neither the exact mechanism(s) of activation nor the sequelae of such inflammation are fully understood.

Complement activation and neutropenia occur during $\mathrm{CPB}$, and functional signs of leukocyte activation after cardiac operation, including the release of proteolytic enzymes, free radical production, and changes in leukocyte adhesiveness, have been reported. ${ }^{4-6}$ Furthermore, measures of cell-mediated immunity, such as lymphocyte responsiveness to mitogens and antigen presentation, have been shown to be seriously impaired in patients after CPB. ${ }^{7}$

The monocyte/macrophage cell system is believed to play a central role in regulating acute inflamma-

1172 
tory responses. During $\mathrm{CPB}$, monocytes release proinflammatory mediators, such as interleukin (IL)-1 $\beta$, IL-6, and IL-8. ${ }^{3,8,9}$ Monocytes express specific cell surface antigens that are of principal importance in stimulation of these myeloid cells. CD14 is a $55-\mathrm{kD}$ glycoprotein that exists in both membrane-associated and soluble forms. Membrane-associated CD14 (mCD14) has been identified as the main lipopolysaccharide (LPS) (endotoxin) receptor on leukocytes. ${ }^{10}$ mCD14 can be released by cells to yield a soluble protein (sCD14) that is able to attach to epithelial and endothelial cells. ${ }^{11}$

Activation of monocytes through mCD14 triggers a complex inflammatory response, leading to cytokine release, production of reactive oxygen species, and production of prostaglandins. Elevated plasma concentrations of sCD14, together with a reduced expression of $\mathrm{mCD} 14$, have been reported in patients with pathologic conditions such as sepsis, infection, or multiple organ failure, and increased serum levels of sCD14 were associated with a higher mortality. ${ }^{12,13}$

Because the systemic inflammatory response to $\mathrm{CPB}$ is mediated, in part, by monocytes and because increased plasma levels of sCD14 reflect monocyte activation we analyzed the effect of elective coronary artery bypass grafting with $\mathrm{CPB}$ on the monocyte CD14 system.

\section{Patients and methods}

Study design. To test the hypothesis that $\mathrm{CPB}$ activates the monocyte CD14 system, markers of monocyte CD14 activity were determined before, during, and after elective coronary revascularization operation performed with CPB. Primary measures of monocyte CD14 activity were the membrane expression of CD14 and plasma concentrations of sCD14. Because CPB may differentially effect the numbers of circulating leukocytes, numbers of leukocytes, monocytes, and monocyte subpopulations were also determined.

Blood samples were collected before anesthesia, after 15 and 60 minutes of $\mathrm{CPB}$, and at $0,6,20$, and 44 hours after completion of the operation. Blood obtained from five healthy donors (mean age $59 \pm 7$ years, three men and two women) was used to establish the normal range of monocyte CD14 activity.

Patients. Ten patients (eight men, two women, mean age $63 \pm 8$ years) with coronary heart disease undergoing elective coronary revascularization participated in the study. The study protocol was approved by the ethical board of the Faculty of Medicine at the Ludwig-Maximilians-University of Munich, and informed consent was obtained from each patient.

None of the patients had clinical evidence of acute infection or underlying immune disease, and none were prescribed drugs known to interfere with the immune response before operation. Anesthesia was accomplished with a standard combination of a narcotic (isoflurane), muscle relaxant (pancuronium bromide), and analgesic (fentanyl). In all patients a polypropylene hollow fiber oxygenator (Maxima Plus PRF, surface area $2.3 \mathrm{~m}^{2}$, ethylene oxide-sterilized, mean priming volume $2280 \mathrm{ml}$, Medtronic, Anaheim, Calif.) was used. The extracorporeal circuit was primed with standard electrolyte solution to which $50 \mathrm{mmol}$ bicarbonate was added. CPB was instituted at a flow rate of $4.0 \pm 0.4 \mathrm{~L} / \mathrm{min}$. Blood was anticoagulated by administration of 20,000 to 30,000 IU of heparin during CPB. The heparin was neutralized by protamine at the end of $\mathrm{CPB}$. The total time on $\mathrm{CPB}$ was $101 \pm 48$ minutes, and the aorta was clamped for an average of $60 \pm 31$ minutes. Minimal body temperature reached was $28.4^{\circ} \pm 3.6^{\circ} \mathrm{C}$ in $50 \pm 31$ minutes after initiation of CPB. A total of $2.6 \pm 0.5$ distal coronary anastomoses were performed.

All patients were extubated on the first postoperative day and transferred from the intensive care unit on the second postoperative day. Two patients had a rethoracotomy within the first postoperative hours because of an intrathoracic hemorrhage, but recovery was uneventful otherwise. Two patients were treated with antibiotics for uncomplicated urinary tract infections at the end of the first postoperative week.

Leukocyte count. The absolute number of total leukocytes was determined by use of a Coulter Counter T 840 (Coulter, Krefeld, Germany).

Immunofluorescence studies. Monocyte expression of CD14 and CD16 was studied using two-color immunofluorescence. Briefly, samples of ethylenediaminetetraacetic acid-anticoagulated blood were drawn and stored on ice for a maximum of 2 hours. Whole blood, $100 \mu \mathrm{l}$, was reacted with monoclonal antibodies against CD14 (My4PE, Coulter) and CD16 (3G8-Fitc, Coulter) or the respective isotype controls for 20 minutes on ice. Erythrocytes were lysed, and the leukocytes fixed using the Q-Prep Lysis Kit (Coulter). Samples were washed twice with cold phosphate-buffered saline and then analyzed in a FACSCan flow cytometer (Becton Dickinson, San Jose, Calif.). Monocytes (5000 events) were acquired by gating on forward and side angle scatter. The percentage of nonviable cells determined by staining with propidium iodide (Sigma, Deisenhofen, Germany) was negligible $(<2 \%)$. For analysis, the data were collected in log mode. The logarithmic data were transformed to a linear scale of specific mean fluorescence intensity, and results are expressed as relative change from preoperative values.

Within the human monocyte/macrophage system, most monocytes are CD16-negative and exhibit strong CD14 staining. These CD14 ++ cells (two ++ to denote the strong expression of CD14) account for about $90 \%$ of all monocytes and represent what is usually referred to as "monocytes." CD14+CD16+ positive cells form a subset of monocytes that is distinct from the classical monocyte population. These cells are characterized by a more mature phenotype and by the inability to produce IL-10. ${ }^{14}$ The number of CD14+CD16+ monocytes can be dramatically increased in patients with sepsis. ${ }^{15}$ Analysis of CD14+CD16+ positive cells was performed as previously 


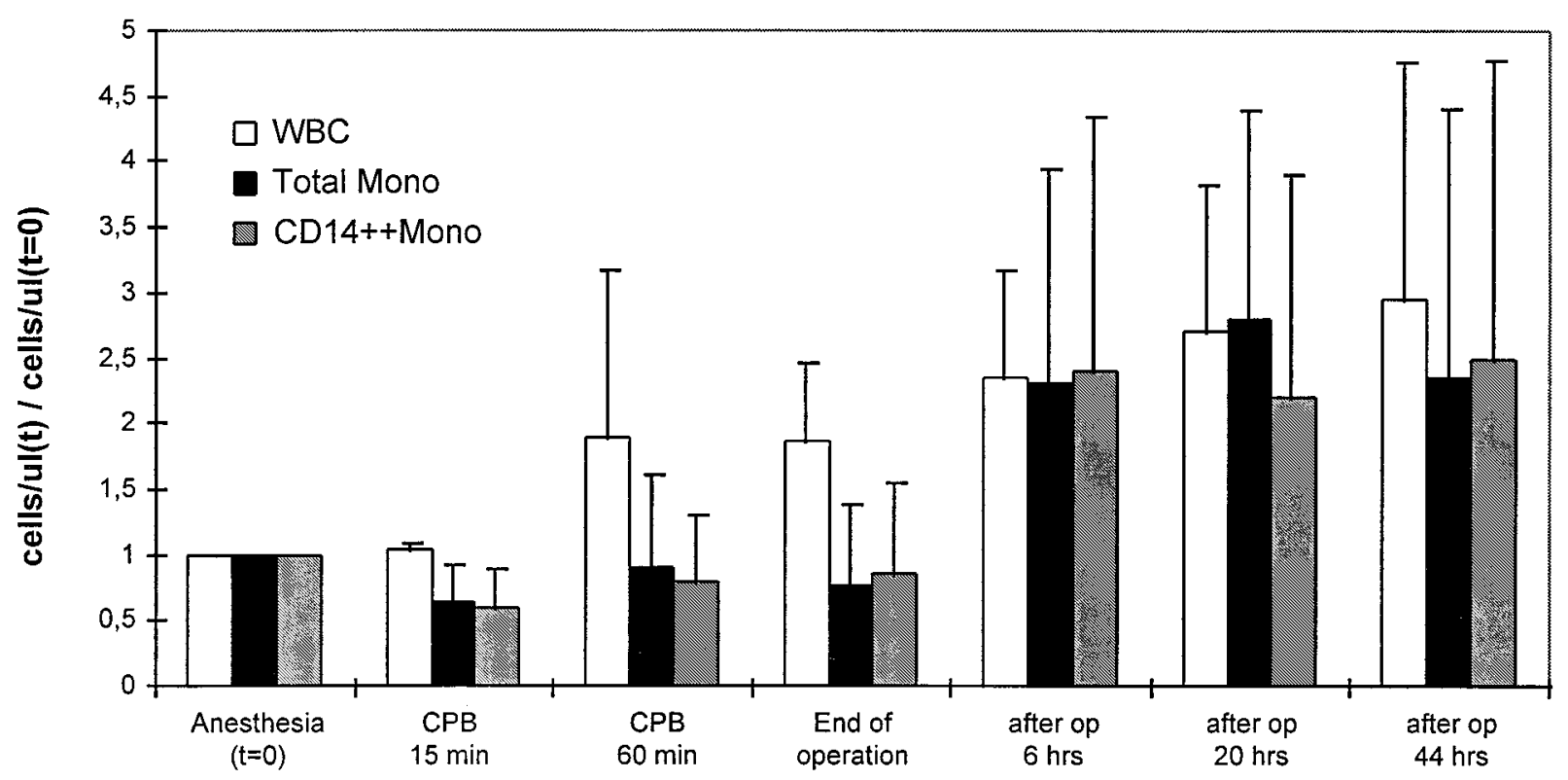

Fig. 1. Relative changes in the absolute numbers of leukocytes, total monocytes, and CD14 ++ monocytes. The absolute numbers of total monocytes and monocyte subpopulations were determined by FACS using directly fluorochrome-conjugated monoclonal antibodies against CD14 (My4-phycoerythrin) and CD16 (3G8-fluorescein). Preoperative values $(t=0)$ were taken as $100 \%$. Subsequent data are given as relative difference to preoperative values $($ cells $/ \mu 1[\mathrm{t}]$ divided by cells $/ \mu \mathrm{l}[\mathrm{t}=0])$, thus reflecting the factor of decrease or increase compared with $t=0 . C P B$, Cardiopulmonary bypass.

described elsewhere ${ }^{16}$ (also in http://www.med.unimuenchen.de/immuno/ziegler). The number of total monocytes/ $\mu$ l blood was calculated as total leukocytes/ $\mu \mathrm{l}$ blood $\times \%$ of all CD14 positive cells in the monocyte scatter gate. The number of CD14+CD16+ monocytes per $\mu \mathrm{l}$ was calculated as total monocytes per $\mu \mathrm{l}$ blood $\times \%$ CD14+CD16+ monocytes among all CD14-positive monocytes.

sCD14 detection by Western blotting. Plasma was obtained by centrifugation of whole blood at $800 \mathrm{~g}$ for 5 minutes at $4^{\circ} \mathrm{C}$ and stored at $-80^{\circ} \mathrm{C}$. For sCD14 analysis, plasma was thawed at $37^{\circ} \mathrm{C}$ and coagulated by addition of glass beads. Western blotting was performed as previously described. ${ }^{17}$ Briefly, plasma was diluted 1:50 with Laemmli's reducing sample buffer, boiled, and loaded onto precast $12.5 \%$ polyacrylamide gels (Phastgels, Pharmacia Biotech, St. Quentin, Yvelines, France). Electrophoresis was carried out in the presence of sodium dodecylsulfate in a PhastSystem (Pharmacia). Proteins were transferred to Hybond-ECL nitrocellulose membranes (Amersham, Buckinghamshire, United Kingdom) in transfer buffer (48 $\mathrm{nmol} / \mathrm{L}$ tris-hydroxymethyl-amino methane, $39 \mathrm{nmol} / \mathrm{L}$ glycine pH 9.0 with the addition of $20 \%$ methanol) for 16 minutes at $30 \mathrm{~mA} / \mathrm{gel}$ using a semidry transfer cell (Bio$\mathrm{Rad})$. sCD14 glycoproteins were detected by incubation of the blots with the My4 monoclonal antibody $(1 \mu \mathrm{g} / \mathrm{ml})$ and visualized by enhanced chemiluminescence (Amersham). Luminescence was detected by short exposures on Hyperfilm MP films (Amersham). With short exposure times of the film, the Western blotting for sCD14 is at least semiquantitative because in titration experiments a linear relationship between amounts of sCD14 and the densitometry signal was achieved.

sCD14 detection by enzyme-linked immunosorbent assay. Plasma concentrations of sCD14 were determined using a specific enzyme-linked immunosorbent assay (IBL, Hamburg, Germany).

Statistics. To determine the effect of CPB on monocyte activity, the time courses of monocyte CD14 expression and plasma CD14 concentrations were analyzed by use of an analysis of variance for repeated measures (SigmaStat, Jandel, San Rafael, Calif.). This method of analysis was chosen in recognition of the variability in monocyte populations that can occur between individuals. Where a significant effect of time was found, differences between individual time points were evaluated using a Bonferroni posthoc test. Data are presented as mean \pm standard deviation. For clarity of presentation, the data presented in Figs. 1 and 2 are normalized to the preanesthesia value.

\section{Results}

CPB induces an initial decrease of monocyte count followed by postoperative monocytosis. Leukocyte and monocyte counts were within normal limits preoperatively $(5.540 \pm 2.093$ leukocytes $/ \mu 1$ and $485 \pm 242$ monocytes/ $\mu \mathrm{l})$. In contrast to earlier reports the total leukocyte count did not decrease significantly after start of CPB. Instead, total leuko- 


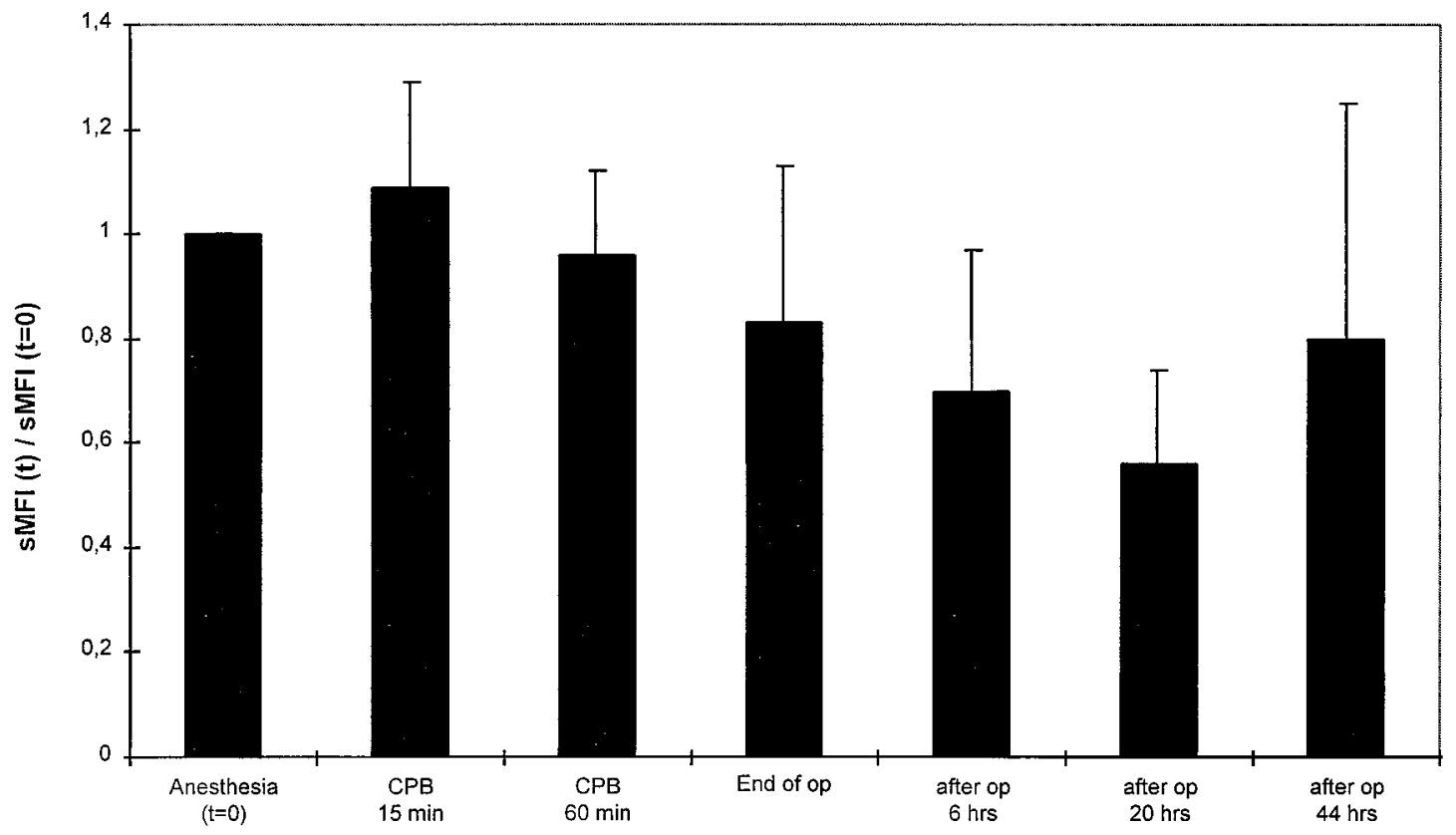

Fig. 2. Expression of mCD14 on CD14++ monocytes. Expression of mCD14 on CD14 + monocytes was analyzed with the monoclonal antibody My4-PE and the respective isotypic control. Preoperative values $(t=0)$ were taken as $100 \%$. Subsequent data are given as relative difference to preoperative values ( $\mathrm{sMFI}[\mathrm{t}]$ divided by $\mathrm{sMFI}[\mathrm{t}=0])$, thus reflecting the decrease compared with $t=0$. Statistical differences are described in the text. $S M F I$, Specific mean fluorescence; $C P B$, cardiopulmonary bypass.

cyte count increased continuously up to factor 3 at 44 hours after operation $(p<0.05)$. Fifteen minutes after initiation of $\mathrm{CPB}$, there was a mild decrease in monocyte count to $305 \pm 237$ cells $/ \mu$ l, followed 6 hours after the end of the operation by a monocytosis that reached a maximum at 20 hours $(1080 \pm$ 264 cells $/ \mu \mathrm{l}, p<0.05$, Fig. 1). Because CPB might differentially influence monocyte subpopulations, we also studied the kinetics of classical CD14++ and CD14+CD16+ monocytes. The major population of $\mathrm{CD} 14++$ monocytes was decreased during $\mathrm{CPB}$, with a nadir at 15 minutes $(272 \pm 214 \mathrm{cells} / \mu \mathrm{l}$ vs $457 \pm 220$ cells/ $/ \mu$ l during anesthesia). At 6 hours after operation the number of CD14+ monocytes in peripheral blood had already increased by a factor of 2.5, reaching a maximum at 20 hours with $911 \pm$ 369 cells $/ \mu$ l $(p<0.05$, Fig. 1$)$. The CD14+CD16+ monocytes $(48 \pm 30$ cells $/ \mu$ l initially $)$ decreased, with a nadir at the end of operation $(9 \pm 6$ cells $/ \mu l)$ and increased after operation by factor 1.5 with a maximum of $69 \pm 33$ cells $/ \mu \mathrm{l}$ at 20 hours after operation (data not shown). Thus in the postoperative phase there is a relative decrease of $\mathrm{CD} 14+\mathrm{CD} 16+$ monocytes, which is maximal at 6 hours after operation $(9.3 \% \pm 2.4 \%$ vs $2.9 \% \pm$
$2.1 \%, p<0.001)$ and still persists at 20 hours $(6.7 \%$ $\pm 3.3 \%$ ) (data not shown).

mCD14 expression decreases on CD14++ monocytes after CPB. Before operation, mCD14 expression by $\mathrm{CD} 14++$ monocytes was within the normal range compared with five healthy donors. After the start of $\mathrm{CPB}$, a temporary increase in $\mathrm{mCD} 14$ expression was noted (Fig. 2). mCD14 expression then decreased, reaching a nadir $40 \%$ below initial values at 20 hours postoperatively $(p<0.05)$. The $\mathrm{CD} 14+\mathrm{CD} 16+$ monocytes are not included in the above analysis. Cell surface expression of mCD14 did not significantly change in the CD14+CD16+ monocytes (data not shown).

Plasma sCD14 is increased at the time of low monocyte mCD14 expression. At the time of maximal mCD14 suppression, the levels of sCD14 were clearly increased by factor of 1.7 (before CPB $3.2 \pm$ 1.0 vs $5.6 \pm 1.0 \mu \mathrm{g} / \mathrm{ml} 20$ hours after operation, $p<$ 0.001 , Fig. $3, A$ ). Levels of sCD14 in plasma (total sCD14) derive from a small membrane form of CD14 (sCD14 $\alpha)$ and from intracellular pools $(\mathrm{sCD} 14 \beta) \cdot{ }^{17}$ In our study no significant change was found in the relative contribution of the $\alpha$-form and the $\beta$-form to total sCD14 levels $(\alpha$-sCD14: at 0 

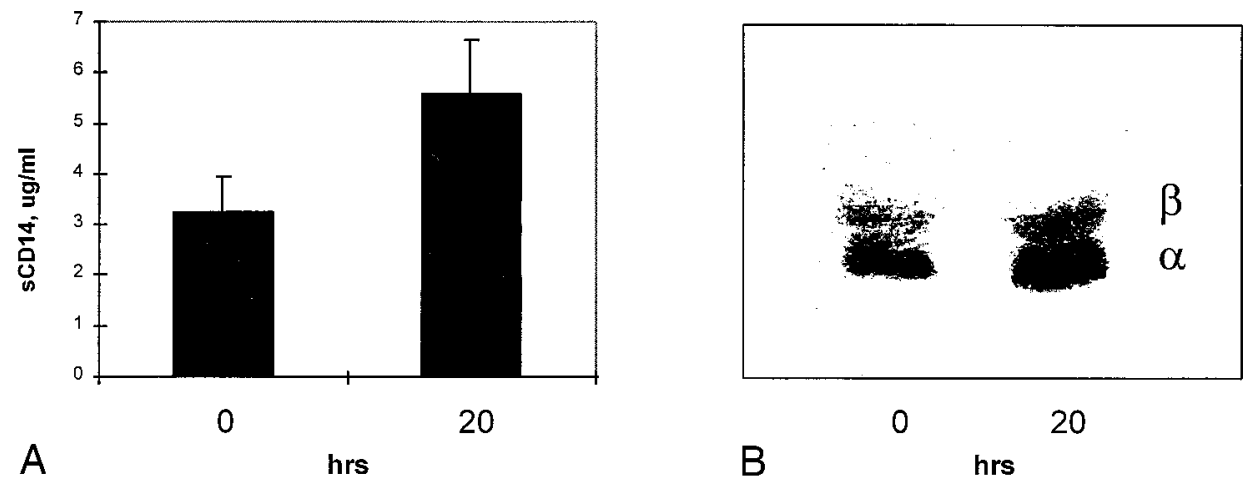

Fig. 3. Levels of sCD14 before and 20 hours after aorta-coronary bypass operation. A, Total levels of sCD14 were determined by Western blotting at 0 hours and 20 hours after operation with the My4 monoclonal antibody and were visualized by enhanced chemiluminescence. Values are given as mean \pm standard deviation. Statistical differences are described in the text. B, Representative Western blot of the $\alpha$-form and $\beta$-form of SCD14 in patient No. 1 at 0 hours and 20 hours after operation. Here, the $\alpha$-form (lower band) accounts for 59\% of total sCD14 before and 64\% 20 hours after operation.

hours $55 \% \pm 2 \%$ of total vs $51 \% \pm 3 \%$ of total 20 hours after). In Fig. 3, B, representative data obtained from one patient are shown. In this patient the relative contribution of $\mathrm{sCD} 14$ to total $\mathrm{sCD} 14$ was essentially constant (59\% at 0 hours and $64 \% 20$ hours after operation). Thus secretion of intracellular material and shedding of mCD14 from the monocyte surface appear to contribute equally to the increase of total sCD14.

\section{Discussion}

Despite considerable progress in the use of CPB, the so-called postperfusion syndrome still plays a role in the morbidity and mortality of patients undergoing cardiac operations, particularly after prolonged extracorporeal circulation. The underlying mechanism(s) of this inflammatory response is still not fully understood. Functional and phenotypic signs of leukocyte activation during extracorporeal circulation for cardiac operation have been reported previously. ${ }^{1,2}$ In this regard leukocyte-mediated vascular endothelial damage is believed to play a major role, with most of the studies focused on the generation of activated complement components (C5a) or the release of leukocyte-derived cytokines (IL-1, IL-6, IL-8, tumor necrosis factor- $\alpha$ ).

Besides generation of proinflammatory soluble cell products, monocytes express a specific $55-\mathrm{kD}$ glycoprotein on their surface, the CD14 antigen that exists in both the membrane-associated and soluble form. The CD14 antigen system is of principal importance in stimulation of monocytes by endo- toxin and endotoxin-like substances. In this study the effect of cardiac bypass operation on the monocyte CD14 system was investigated.

Herein a profound alteration of the monocyte CD14 system was found in patients undergoing elective coronary revascularization. After cardiac operation with the use of CPB, a significant monocytosis was observed, reaching a maximum at 20 hours after operation. In parallel to this increase of monocyte cell number, a decrease of mCD14 antigen expression and a significant increase in levels of sCD14 antigen occurred in all patients studied.

Bacterial LPS is a potent activator of leukocytes, with CD14 on the cell membrane as the main LPS receptor. LPS may associate with soluble serum proteins (LPS binding protein) before the resulting complex is bound by mCD14, leading to characteristic cell responses such as synthesis and release of inflammatory mediators. In addition, CD14 can be released by leukocytes, and the soluble form of CD14 has been shown to enable responses to LPS by cells that do not express CD14 as an LPS receptor, ${ }^{18}$ as well as by mCD14-bearing cells. ${ }^{19,20}$ These activities indicate that the membrane form behaves as an LPS receptor, and its soluble pendant may serve as a coligand for LPS-mediated cell activation.

The decrease of membrane CD14 on blood monocytes and the concomitant increase of sCD14 in plasma reported herein suggest that the $\mathrm{SCD} 14$ is derived from monocytes by shedding of the cell surface molecule. In addition, it is possible that tissue macrophages contribute to the increased 
sCD14 by the same mechanism. At this point it is, however, not known whether mCD14 of tissue macrophages also becomes down-regulated after CPB.

Although anti-CD14 monoclonal antibodies preferentially stain monocytes and macrophages, reactivity with other cells, such as granulocytes, B cells, and mammary cells, is also observed. ${ }^{21}$ Besides activation of monocytes, CPB may lead to significant alterations in granulocytes. Indeed, increased plasma concentrations of granulocyte proteinases and oxygen radicals have been reported. ${ }^{22}$ Therefore granulocytes and monocytes should be considered as the source of sCD14 found after CPB.

CD14 in plasma is found as a mixture of two soluble proteins, the smaller molecular weight sCD $14 \alpha$, deriving mainly from membrane-bound protein material by shedding, and the larger molecular weight $\mathrm{sCD} 14 \beta$, released from intracellular pools. ${ }^{17}$ In this study we found no significant difference in the ratio of the $\alpha$ and the $\beta$ forms of sCD14 between samples taken before and after operation. These results indicate that secretion of intracellular material and shedding of mCD14 contribute equally to the increase of total sCD14 found in plasma after coronary bypass operation.

In vitro LPS stimulation of monocytes induces an increase of mCD14 expression within 30 minutes followed by a slow decrease after 1 to 3 hours. ${ }^{23}$ Furthermore, this decrease of mCD14 coincides with an enhanced sCD14 release by the stimulated cells. ${ }^{24}$ In our study a transient increase of mCD14 expression immediately after the start of $\mathrm{CPB}$ was followed by a continuous decrease of mCD14. Similar to the in vitro results reported, these changes in membrane-bound antigen activity paralleled the increasing levels of sCD14, reaching a maximum at 20 hours after the end of operation. Our results indicate that CPB poses a strong stimulus to previously unaffected circulating monocytes.

Several mechanisms of cell activation during CPB have been proposed. Direct interaction of immunocompetent blood cells with the foreign surfaces of the extracorporeal circuit has been favored as the primary mechanism. ${ }^{1}$ However, with its biologic function as the main LPS receptor on leukocytes, the CD14 system could mediate activation of cells by endotoxin itself. Indeed, in patients undergoing $\mathrm{CPB}$, increased intestinal permeability and significantly elevated levels of plasma endotoxin activity measured by the Limulus amebocyte lysate assay have been reported. ${ }^{25}$ Furthermore, as found with other extracorporeal circuits, such as hemodialysis and hemofiltration, monocyte activation could be due to contamination of blood, tubing lines, the membrane oxygenator, or the priming solution with endotoxin or endotoxin-like material. ${ }^{26}$ Interestingly, a reduced expression of mCD14, together with elevated serum levels of sCD14, was also described in patients undergoing intermittent hemodialysis. ${ }^{27}$ In addition, the operative trauma itself, ischemiareperfusion injury caused by crossclamping of the aorta, and reinfusion of shed blood could contribute to the cell-activating process.

On the basis of our results, we speculate that endothelial cell responses after CPB occur through different pathways. One pathway, probably the principal pathway, is activation of monocytes through mCD14 triggering a complex inflammatory response, including the production and release of cytokines, reactive oxygen species, and prostanoids, all of which are known to be able to induce vascular endothelial cell damage directly. In addition, activation of the CD14 system could induce increased shedding and release of sCD14. The soluble form of CD14 then could interact with endothelial cells, promoting cell activation indirectly in concert with inflammatory cytokines. ${ }^{21}$ In our study we did not include the measurement of cytokine production. However, in patients with sepsis, LPS-mediated signaling and cytokine transcription were reported unchanged despite a significant decrease of CD14 expression on blood monocytes. ${ }^{28}$ Finally, endothelial cell activation and damage may also be induced by direct leukocyte endothelial interaction mediated by adhesion molecules. ${ }^{29}$

In conclusion, our results demonstrate that cardiac operation with the use of CPB results in significantly decreased mCD14 and elevated sCD14 levels, indicating a profound derangement of the CD14 receptor system. The clinical importance of these findings is not yet clear. In septicemic patients both decreased as well as unchanged CD14 expression by blood monocytes has also been reported. ${ }^{16,30}$ These different results might be explained by different subsets of patients or different times of cell surface antigen analysis. Furthermore, elevated plasma levels of sCD14 were associated with a higher mortality in patients with sepsis or multiple organ failure. However, whether these changes contribute to a quantitative and functional impairment of the immune response in patients undergoing cardiac operation cannot be concluded from this study. 
We thank A. Frank-Wanger and J. Köbler for expert technical assistance and R. A. Ward for his assistance in the preparation of the manuscript.

\section{REFERENCES}

1. Kirklin JK, Westaby S, Blackstone EH, Kirklin JW, Chenoweth DE, Pacifico AD. Complement and the damaging effects of cardiopulmonary bypass. J Thorac Cardiovasc Surg 1983;86:845-57.

2. Nilsson L, Brunnkvist S, Nilsson U, Nyström SO, Tyden $\mathrm{H}$, Venge $\mathrm{P}$, et al. Activation of inflammatory systems during cardiopulmonary bypass. Scand J Thorac Cardiovasc Surg 1988;22:51-3.

3. Weerwind PW, Maessen JG, van Tits LJH, Stad RK, Fransen EJ, de Jong DS, et al. Influence of duraflo II heparin-treated extracorporeal circuits on the systemic inflammatory response in patients having coronary bypass. J Thorac Cardiovasc Surg 1995;110:1633-41.

4. Hammerschmidt DE, Stroncek DF, Bowers TK, LammiKeefe CJ, Kurth DM, Ozalins A, et al. Complement activation and neutropenia occurring during cardiopulmonary bypass. J Thorac Cardiovasc Surg 1981;81:370-7.

5. Dapper F, Neppl H, Wozniak G, Strube I, Boldt J, Hehrlein $\mathrm{FW}$, et al. Influence of 4 different membrane oxygenators on inflammation-like processes during extracorporeal circulation with pulsatile and non-pulsatile flow. Eur J Cardiothorac Surg 1992;6:18-24.

6. Hind CRK, Griffin JF, Pack S, Latchman YE, Drake HF, Jones HM, et al. Effect of cardiopulmonary bypass on circulating concentrations of leucocyte elastase and free radical activity. Cardiovasc Res 1988;22:37-41.

7. Markewitz A, Faist E, Weinhold C, Lang S, Endres S, Hültner L, et al. Alterations of cell-mediated immune response following cardiac surgery. Eur J Cardiothorac Surg 1993; 7:193-9.

8. Haeffner-Cavaillon N, Roussellier N, Ponzio O, Carreno M-P, Laude M, Carpentier A, et al. Induction of interleukin-1 production in patients undergoing cardiopulmonary bypass. J Thorac Cardiovasc Surg 1989;98:1100-6.

9. Kalfin RE, Engelmann RM, Rousou JA, Flack JE, Deaton DW, Kreutzer DL, et al. Induction of interleukin- 8 expression during cardiopulmonary bypass. Circulation 1993;88: 401-6.

10. Wright SD, Ramos RA, Tobias PS, Ulevitch RJ, Mathison JC. CD14, a receptor for complexes of lipopolysaccharide (LPS) and LPS binding protein. Science 1990;249:1431-3.

11. Pugin J, Schürer-Maly CC, Leturcq D, Moriatry A, Ulevitch RJ, Tobias PS. Lipopolysaccharide activation of human endothelial and epithelial cells is mediated by lipopolysaccharide-binding protein and soluble CD 14. Immunology 1993;90:2744-8.

12. Burgmann H, Winkler S, Locker GJ, Presterl E, Laczika K, Staudinger T, et al. Increased serum concentration of soluble CD14 is a prognostic marker in Gram-positive sepsis. Clin Immunol Immunopathol 1996;80:307-10.

13. Landmann R, Zimmerli W, Sansano S, Link S, Hahn A, Glauser MP, et al. Increased circulating soluble CD14 is associated with high mortality in Gram-negative septic shock. J Infect Dis 1995;171:639-44.

14. Ziegler-Heitbrock HWL. Heterogeneity of human blood monocytes: the CD14+CD16+ subpopulation. Immunology Today 1996;17:424-8.

15. Blumenstein $M$, Boekstegers $P$, Fraunberger $P$, Andreesen R, Ziegler-Heitbrock HWL, Fingerle-Rowson G. Cytokine production precedes the expansion of CD14+CD16+ monocytes in human sepsis. Shock 1997;8:73-5.

16. Fingerle G, Pforte A, Passlick B, Blumenstein M, Ströbel M, Ziegler-Heitbrock HWL. The novel subset of CD14+/ CD16+ blood monocytes is expanded in sepsis patients. Blood 1993;82:3170-6.

17. Durieux JJ, Vita N, Popescu O, Guette F, Calzada-Wack J, Munker J, et al. The two soluble forms of the lipopolysaccharide receptor, $\mathrm{CD} 14$ : characterization and release by normal human monocytes. Eur J Immunol 1994;24:2006-12.

18. Frey EA, Miller DS, Jahr TG, Sundan A, Bazil V, Espevik T, et al. Soluble CD14 participates in the response of cells to lipopolysaccharide. J Exp Med 1992;176:1665-71.

19. Labeta MO, Durieux JJ, Fernandez N, Herrmann R, Ferrara P. Release from a human monocyte-like cell line of two different soluble forms of the lipopolysaccharide receptor, CD14. Eur J Immunol 1993;9:2144-51.

20. Ziegler-Heitbrock HWL, Ulevitch RJ. CD14: cell surface receptor and differentiation marker. Immunol Today 1993; 14:121-5.

21. Vita N, Lefort S, Sozzani P, Reeb R, Richards S, Borysiewicz LK, et al. Detection and biochemical characteristics of the receptor for complexes of soluble CD14 and bacterial lipopolysaccharide. J Immunol 1997;158:3457-62.

22. Antonsen S, Branslund I, Clemensen S, Sofeldt S, Madsen T, Alstrup P. Neutrophil lysosomal enzyme release and complement activation during cardiopulmonary bypass. Scand J Thorac Cardiovasc Surg 1987;21:47-52.

23. Marchant A, Duchow J, Delville JP, Goldman M. Lipopolysaccharide induces up-regulation of CD14 molecule on monocytes in human whole blood. Eur J Immunol 1992;22: 1663-5.

24. Landmann R, Knopf HP, Link S, Sansano S, Schumann R, Zimmerli W. Human monocyte CD14 is upregulated by lipopolysaccharide. Infect Immun 1996;64:1762-9.

25. Riddington DW, Venkatesh B, Boivin CM, Bonser RD, Elliott TS, Marshall T, et al. Intestinal permeability, gastric intramucosal $\mathrm{pH}$, and systemic endotoxemia in patients undergoing cardiopulmonary bypass. JAMA 1996;275:1007-12.

26. Laude-Sharp M, Caroff M, Simard L, Pusineri C, Kazatchkine MD, Haeffner-Cavaillon N. Induction of IL-1 during hemodialysis: transmembrane passage of intact endotoxins (LPS). Kidney Int 1990;38:1089-94.

27. Nockher WA, Scherberich JE. Monocyte cell-surface CD14 expression and soluble CD14 antigen in hemodialysis: evidence for chronic exposure to LPS. Kidney Int 1995;48:146976.

28. Ertl W, Krombach F, Kremer JP, Jarrar D, Thiele V, Eymann J, et al. Mechanisms of cytokine cascade activation in patients with sepsis: normal cytokine transcription despite reduced CD14 receptor expression. Surgery 1993;114(2):24350.

29. Kuijpers TW, Harlan JM. Monocyte endothelial interactions: insights and questions. J Lab Clin Med 1993;122:641-51.

30. Astiz M, Saha D, Lustbader D, Lin R, Rackow E. Monocyte response to bacterial toxins, expression of cell surface receptors and release of anti-inflammatory cytokines during sepsis. J Lab Clin Med 1996;128:594-600. 